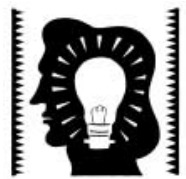

\title{
special articles
}

Psychiatric Bulletin (2005), 29, 65-66

\section{JOAN SMITHIES}

\section{Changing jobs at 50}

As I was celebrating my 50th birthday in March 2003, I was serving out my notice in the job I had held for 17 years as a consultant in old age psychiatry for a population of 18500 and latterly as trust deputy medical director for elderly mental health.

My decision to change jobs was not made lightly or suddenly, but came about as a process of evolution over a couple of years. Quite simply, I had become bored. Bored with bashing my head against the same brick walls, bored by the lack of opportunity for personal development, as I saw it, owing to a crushingly large clinical workload. I missed the stimulus of the learning disability work that I had had to give up because of workload pressures some years before. We were hopelessly undermanned, with only six consultants for an elderly population of 110000 . The trust's medical staffing strategy allowed for only one additional consultant this side of my earliest retirement date, although there was an acknowledgement that after my retirement I could not be replaced by just one person! I envied my own children, on the brink of new and exciting lives. I began to long for retirement and to plan what I would do when I retired.

The pressure of my job, particularly the deputy medical director role, increased sharply towards the end of 2002 when first one and then a second of my five colleagues resigned and moved elsewhere. They left largely for personal and family reasons, but with catchment area sizes of 19000 and 16500 it was obvious that their existing job descriptions would not be approved by the College. We approached a local primary care trust for funding for an extra consultant post. The message 'there is no more money for elderly mental health consultants' came back to me indirectly through my own trust management. I felt angry and utterly taken for granted.

With a third consultant making plans to leave and a fourth due to retire in 2 years, 1 faced the prospect of being at the helm of a sinking ship, its crew consisting mainly of a series of locums.

However, I then read a series of articles in the BMJ by Anita Houghton (Houghton, 2002), and began to systematically review and re-evaluate my working life. It seemed to me that (borrowing Dr Houghton's terminology) I was allowing myself to be run by certain 'limiting beliefs' that were keeping me stuck in my current job. For instance, I believed that I was essential and irreplaceable, and that I was too old and too near retirement to be seriously considered in the job market. I still enjoyed aspects of my work, especially the patient contact, but I desperately wanted more time for reflection and personal development. Increasingly, the classified section was the first part of the BMJ I turned to each week, 'just out of interest'.

I heard on the grapevine that a new consultant post had been created in a neighbouring trust, joining an existing consultant who was running a lively, communitybased, largely rural service that had won the 'Hospital Doctor of the Year' award in the psychiatry category a few years previously. I decided to telephone and express an interest in the job. This was really the most daunting part of the whole process, as I had no idea whether the existing consultant would want an older, experienced colleague. In fact he welcomed my interest and I went ahead and applied. It felt odd to be on the receiving end of the job application process, having sat countless times over the years on the interviewer's side; but that experience must have stood me in good stead, because I received very positive feedback about my interview performance and was asked if I would consider contributing to some training in interview technique for specialist registrars!

What can I say now that I have completed 6 months in post? There are things I miss greatly about my previous post: some of my old colleagues, and the excellent, innovatory social services I used to work with. On the other hand, I love being able to offer cholinesterase inhibitors to all patients who might benefit from them and who meet the National Institute for Clinical Excellence guidelines. In my previous job, there were strict numerical limits on prescribing - I found it extremely frustrating to watch patients cognitively declining on a waiting list and to feel that my only useful role was to advise their carers about the complaints procedure.

I like the open management style of my new trust, and the fact that consultation is genuine and not just an exercise to be gone through after important decisions have already been made at a higher level. Although the workload is heavier than I was expecting, I do have more time for reflection and personal development. My IT skills have improved enormously, thanks to the trust's excellent IT provision, training and support. There are good links with the local university and I am looking forward to my role in teaching third year medical students, for which 
(1)

special articles again local training is provided. I am able to use some of my management skills and experience, for example by joining the trust's list of consultant appraisers, and I am enjoying a new role as lead elderly mental health consultant for electroconvulsive therapy.

What is the same? The challenge of maintaining morale in the NHS, of supporting colleagues, of battling with finite resources. Although our service functions well and is staffed by enthusiastic and committed people, nowhere in the NHS is entirely without problems. However, because I am so new I do not feel responsible in any way for the evolution of these problems, which gives me a freshness and enthusiasm in helping to tackle them that I had lost in my old job.

What of my old trust? Has the old age psychiatry service collapsed and disintegrated without me? Well, no. The one remaining consultant not close to retirement has taken on the lead clinician role with tenacity and flair. The consultant establishment has increased from 6 to 8 , and although some of the service is run by locums, some promising new appointments have been made. My old job is now covered by the associate specialist whom I worked with for years, now acting very capably as locum consultant. Not only am I not indispensable, but my departure has created new opportunities for individuals and triggered a consultant expansion that was long overdue.

In Susan O'Connor and Christine Vize's recent Psychiatric Bulletin article (O'Connor \& Vize, 2003), the crisis in recruitment and retention of consultant psychiatrists is described from the point of view of medical management. They reiterate the commonly held opinion that consultants change posts in pursuit of smaller workloads and more attractive working conditions. In my own case, the motivation was indeed to move to a job with a smaller, more manageable workload - even at a lower salary. My working life improved at least as much as I had hoped; but not because of the reduction in workload, which is not as much as I had expected. Rather, I now realise that the main factors are first, that I am now able to treat patients as I would wish, and second, that the consultative management style allows me to make a genuine and valued contribution towards the management and development of services. It also makes proper use of the knowledge and skills that I have acquired over many years of consultant practice. This fits well with Herzberg's principle (Herzberg, 1966) that while people tend to cite intrinsic features of their work (fulfilment, respect etc.) as causes of job satisfaction, when they are dissatisfied they tend rather to blame extrinsic factors such as pay, workload and conditions.

Attempts to solve the current crisis in recruitment and retention have concentrated on those factors which are thought to contribute to poor job satisfaction, such as excessive workload, lack of support, etc. Perhaps a more productive approach would be to look at those consultants who are happy and fulfilled in their work (hopefully not too small a sample to be significant!) and to try to draw some general lessons from their experience.

\section{References}

HERZBERG, F. (1966) Work and the Nature of Man. London: Harper Collins.

HOUGHTON, A. (2002) How do we limit ourselves? British Medical Journal, 324 S107.

O'CONNOR, S. \& VIZE, C. (2003) The 'Catch-22' of recruitment and retention in psychiatry. Psychiatric Bulletin, 27, $443-445$.

Joan Smithies Consultant Psychiatrist, Becton Centre, The Fairway, Barton on Sea, Hampshire BH25 7AE (e-mail: drjoan@btopenworld.com) 